\section{SMGrøup}

\section{SM Journal of Urology}

Article Information

Received date: Aug 25, 2016

Accepted date: Sep 10, 2016

Published date: Sep 13, 2016

*Corresponding author

Ashok Kumar Gupta, MS, M.Ch

(Resident), King George's Medical University, Lucknow, Uttar Pradesh, India, Tel: +91 7054414627;

Email:dr.akgupta555@gmail.com

Distributed under Creative Commons CC-BY 4.0

Keywords RCC; Paraneoplastic syndrome; Diarrhoea

Article DOI 10.36876/smju.1018

\title{
Diarrhoea as a Presenting Feature of Renal Cell Carcinoma, a Case Report and Review of Literature
}

\author{
Ashok Kumar Gupta $^{1 \star}$, Bimalesh Purkait ${ }^{1}$, Kawaljit Singh $^{1}$, Ashok Kumar Sokhal ${ }^{1}$ \\ and Durgesh Kumar Saini ${ }^{1}$ \\ ${ }^{1}$ Department of urology, King George's Medical University, Lucknow, Uttar Pradesh, India
}

\section{Abstract}

Presentation of renal cell carcinoma is quite variable. Only in $10 \%$ cases, it present with classic features of flank mass, hematuria and pain. Uncommon presentation may mislead the diagnosis and management. We are reporting a patient who initially present with diarrhoea as presenting symptoms of renal cell carcinoma.

\section{Introduction}

Approximately $3 \%$ of adult malignant neoplasm is accounted by Renal Cell Carcinomas (RCC) which closes to $90 \%$ of all renal neoplasm [1]. About 10-40\% of RCC patients develop paraneoplastic syndrome. Paraneoplastic syndromes associated with RCC include fever, weight reduction, cachexia, hypercalcemia, hypertension, polycythemia, Stauffer syndrome (non metastatic elevation of liver enzymes), Cushing's syndrome and abnormalities in glucose metabolism, amyloidosis, anemia, neuromyopathies, dermatomyositis, galactorrhea, and glomerulopathies. [2-4]. Few hormones (1, 25-dihydroxycholecalciferol, renin, erythropoietinm) and various prostaglandins are produced from kidney. Various cytokines and inflammatory mediators are responsible for the development of constitutional symptoms such as weight loss, fever, and anaemia in renal cell carcinoma. Paraneoplastic syndrome may be initial presentation or may represent recurrence of RCC [3]. Only two cases have been reported about diarrhoea as a paraneoplastic syndrome. Hence we report a case of RCC in whom persistent diarrhoea resolved after radical nephrectomy. Our case is unique in the sense that, even organ confined RCC can present with paraneoplastic syndrome of diarrhoea as their initial manifestation.

\section{Case Presentation}

A 56-year-old man presented to us with a 9 month history of diarrhoea. He reported three to four stools per day, which was watery in nature associated with vague abdominal pain. He also reported weight loss of about 7 kilogram over a 9 months period. He had no history of fever, nausea, vomiting, melena or hematuria. There was no history of drug abuse though he was a chronic smoker for last 30 years. Family history did not reveal anything. On general survey, he is anaemic, his vitals were found to be normal \& no lymphadenopathy was found. Abdominal examination revealed a ballot-able right flank mass of size about 10x12 cm moving with respiration. Rest of systemic examination were normal. Initially he was evaluated in gastroenterology department. Stool tests were negative for ova, cyst, parasites, WBCs, culture, \& faecal occult blood test. His haemoglobin $9.2 \mathrm{mg} / \mathrm{dl}$, TLC counts $9300 /$ cumm, serum creatinine $1.1 \mathrm{mg} / \mathrm{dl}$. Complete urinalysis, liver function tests, erythrocyte sedimentation rate were within normal range. He had dyselectrolytemia with mild hypokalemia (3.0 meq/lit) and mild hyponatremia (125 meq/lit). Further test like C-reactive protein, TSH, and celiac profile (anti transglutaminase IgA antibody test) \& HIV $1 \& 2$ were also negative.

\section{OPEN ACCESS}
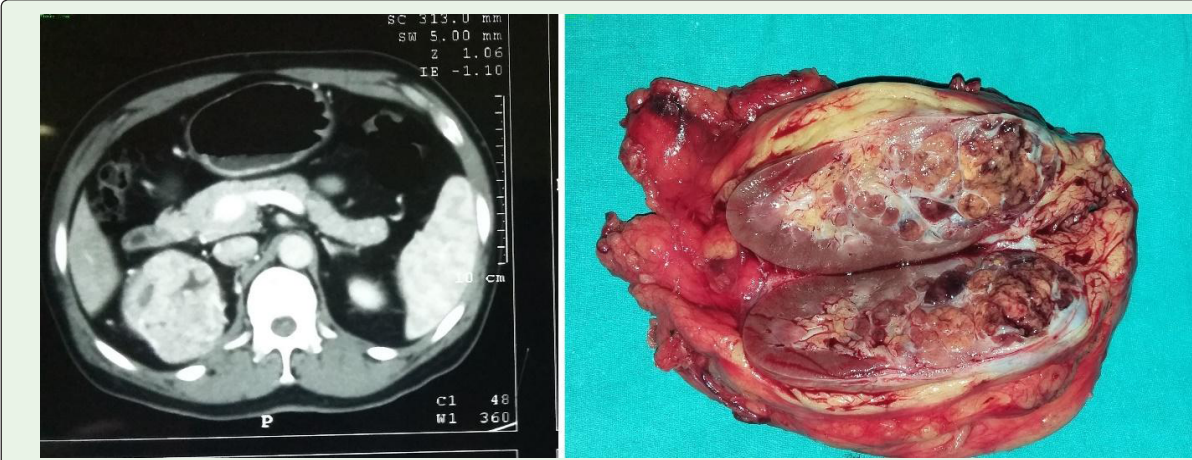

Figure 1: Contrast enhanced abdominal CT, showing heterogeneous, enhancing right upper \& midpolar renal mass, and cut section of gross specimen showing infiltrating upper and midpolar renal mass. 


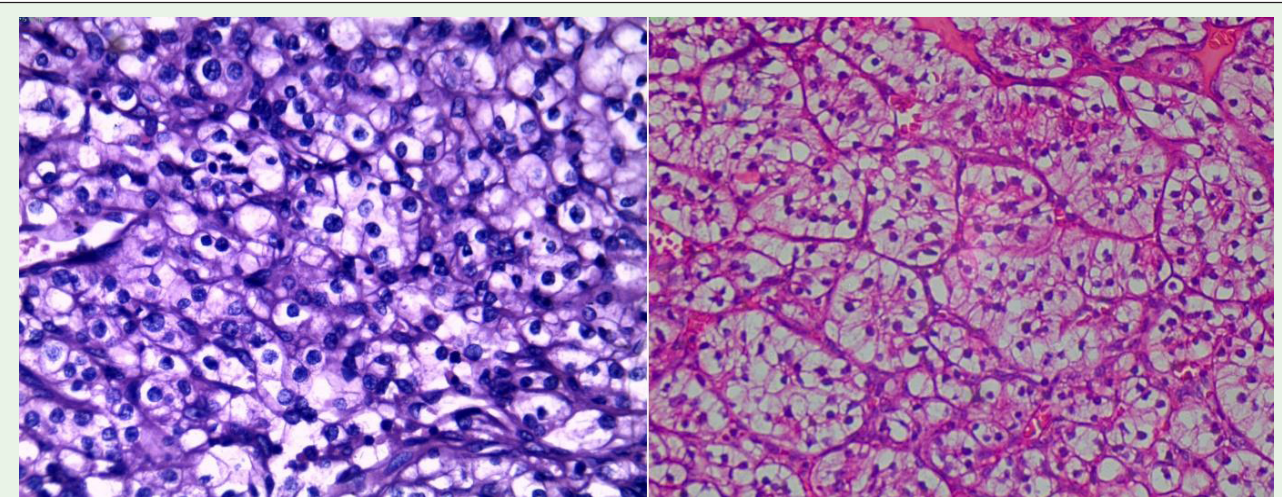

Figure 2: Final histopathology slides showing RCC cells in an alveolar arrangement with clear cytoplasm and distinct cell membranes consistent with RCC -clear cell variant. (Low power and high power magnification).

Ultrasound of whole abdomen showed large right hypo-echoic, heterogenous mass lesion of right kidney with normal left kidney. On further evaluation with contrast enhanced CT scan of abdomen and pelvis, he was found to have a right renal mass, measuring 9x6 cm (Figure 1A-B). Mass was heterogeneous, partially necrotic with mild stranding in the perinephric fat with normal right renal vein with no evidence of large or small intestinal mass or ascites. Colonoscopy was not done as CECT Abdomen did not reveal any large intestinal mass. Metastatic work up including chest X ray, LFT and CT scan for liver metastases were within normal limits. Bone scan was not done as patient did not report any bone pain and serum alkaline phosphatase was within normal range. After proper counselling laparoscopic right radical nephrectomy was carried out uneventfully and specimen was sent to pathology department of our institute. Gross examination revealed 8x6.5 $\mathrm{cm}$ mass infiltrating mid and upper polar mass (Figure 1B). Histopathlogical examination, both under low and high power magnification revealed, clear cell variant of RCC (pT2N0 Mx) with no involvement of renal sinus, adrenal gland and uninvolved gerota's fascia and renal vein was also free of tumour thrombus (Figure 2A-B). Immunohistochemistry could not be done as this facility is costly and not available in our institute. Post operative period was uneventful and diarrhoea resolved completely. Post operative follow up at 6 month was unremarkable with normal bowel habits.

\section{Discussion}

RCC has been described in the literature as the commonest and most lethal genitourinary malignancy, contributing $2 \%$ of all cancer related death [5]. Due to its myriad manifestation and associated paraneoplastic syndromes RCC is also labelled as great imitator or internist's tumour in medical literature. During evaluation of diarrhoea, we found RCC in this patient and diarrhoea resolved completely following nephrectomy. Diarrhoea has been reported to be associated with many neoplastic condition including RCC, vipoma and gastric adenocarcinoma. Secretory diarrhea is also associated with hormones such as increased secretion of serotonin in carcinoid, calcitonin in medullary thyroid carcinoma, and a not fully identified substance produced by tumors of the sympathetic nervous system. In addition to stimulating intestinal secretion, serotonin also increases bowel motility, which contributes to the diarrhea associated with the malignant carcinoid syndrome. So diarrhoea can be a paraneoplastic syndrome of RCC in our patient. Our case is the third reported case of RCC presenting with diarrhoea. A similar case study by Rold reported complete resolution of diarrhoea after nephrectomy in a patient with a case of RCC with diarrhoea and weight loss [6]. Chataut et al [7] have also reported a similar case but patient had regional lymph node metastasis, but our case is unique in the sense that, it was an organ confined non metastatic tumour with no lymph node metastasis, reinstating the fact that even organ confined RCC can present with diarrhoea as paraneoplastic syndrome. The cause of diarrhoea in RCC is not proven but it may be result of production of prostaglandins $\left(\mathrm{PGE}_{1}\right.$ and $\left.\mathrm{PGA}_{1}\right)$ \& vasoactive intestinal peptide [8-10].

\section{Conclusion}

Physician should keep in mind that rarely diarrhoea may be the initial presentation of RCC as a paraneoplastic manifestation.

\section{Acknowledgement}

We acknowledge the guidance \& help of our head of the department, prof SN Sankhawar (MCh) for guiding \& helping us to operate this case.

\section{References}

1. Jemal A, Siegel R, Xu J, Ward E. Cancer statistics, 2010. CA Cancer J Clin. 2010; 60: 277-300.

2. Sacco E, Pinto F, Sasso F, Racioppi M, Gulino G, Volpe A, et al. Paraneoplastic syndromes in patients with urological malignancies. Urol Int.2009; 83: 1-11.

3. Papac RJ, Poo-Hwu WJ. Renal cell carcinoma: a paradigm of lanthanic disease. Am J Clin Oncol. 1999; 22: 223-231.

4. Palapattu GS, Kristo B, Rajfer J. Paraneoplastic syndromes in urologic malignancy: the many faces of renal cell carcinoma. Rev Urol. 2002; 4: 163170.

5. Siegel R, Ward E, Brawley O, Jemal A. Cancer statistics, 2011: the impact of eliminating socioeconomic and racial disparities on premature cancer deaths. CA Cancer J Clin. 2011; 61: 212-236.

6. Benítez Roldán A, González López C, Torres Olivera F, Vallejo Benítez A, Pellicer Bautista F, Herrerías Gutiérrez JM. Diarrhea syndrome and renal cell carcinoma. Rev Esp Enferm Dig. 2008; 100: 505-506.

7. Chataut CP, Ramesh KC, Mullane M, Firfer BL, Shah BK. Diarrhea as the presenting symptom of renal cell carcinoma. Acta Oncol. 2011; 50: 732-733.

8. Metz SA, McRae JR, Robertson RP. Prostaglandins as mediators of paraneoplastic syndromes: review and up-date. Metabolism. 1981; 30: 299316.

9. Ebeid AM, Murray PD, Fischer JE. Vasoative intestinal peptide and the watery diarrhea syndrome. Ann Surg. 1978; 187: 411-416.

10. Racusen LC, Binder HJ. Effect of prostaglandin on ion transport across isolated colonic mucosa. Dig Dis Sci. 1980; 25: 900-904. 